\title{
The Analysis of Main Parameters on Shear Capacity of Steel Tube Steel Reinforced Concrete Composite Column
}

\author{
Bing WANG ${ }^{1, a}$, Xiao LIU ${ }^{1, b,{ }^{*}}$, Tian-Cheng $X U^{1, c}$ \\ ${ }^{1}$ School of Architectural and Civil Engineering, Shenyang University, Shenyang, 110044, China \\ aliuxiao19740701@sina.com, ${ }^{b} 1643274246 @ q q . c o m,{ }^{c} 15702475009 @ 163 . c o m$ \\ ${ }^{*}$ Corresponding author
}

Keywords: Steel tube steel reinforced concrete composite column, Main parameters, Shear capacity.

\begin{abstract}
In this paper, establishing finite element model of ABAQUS, selecting the reasonable component parameters, we calculate and analyze the shear capacity of the steel tube steel reinforced concrete composite column under the effect of lateral horizontal displacement. It is concluded that increasing the constraint effect coefficient, shear bearing capacity of components increases significantly. The shear capacity of components along with the increase of axial compression ratio and shear span ratio reduces gradually.
\end{abstract}

\section{Introduction}

Steel tube steel reinforced concrete is pouring concrete in steel tube, combining concrete and steel .The internal concrete can enhance the strength and stability of the steel tube. Inserting i-steel inside the component can make it continue to play a strong load-bearing role after the loss of bearing capacity of the outside steel pipe. At the same time, because of the existence of core concrete, it delays the internal steel bone expiry time, which gives people plenty of time to escape the rescue, thereby reducing property and life loss [1-4].

In recent years, the study on the shear capacity of steel tube steel reinforced concrete is mature. the research on axial compression, bias , compression bending, bending performance of round steel pipe steel reinforced concrete columns built-in i-steel is common [5-7]. We analyze the parameter of coefficient of constraint effect. Shear span ratio and axial compression ratio and establish the rule of their effect on bearing capacity using the finite element model of ABAQUS.

\section{Parameter Setting and Analysis of Steel Tube Steel Reinforced Concrete Composite Column}

Steel pipe steel reinforced concrete composite column is made up of steel pipes, i-steel and core concrete the intensity of each part has different effect on shear bearing capacity of steel tube steel reinforced concrete. The shear bearing capacity under various stress state will change .loading direction will also affect the shear bearing capacity .In this article, selecting the constraint effect coefficient, shear span ratio, axial compression ratio, we respectively study their effect on shear bearing capacity of steel tube steel reinforced concrete column.

\section{Component Parameter}

Calculation Method of Component Parameter. (1)calculation method of coefficient of constraint $\theta$

$$
\theta=\frac{A_{t} f_{t y}}{A_{c} f_{c k}}
$$

In the formula, $A_{t}$ - the area of steel tube, $A_{c}$ - the area of concrete, $f_{t y}$ - the yield strength of steel tube, $f_{c k}$ - the axial compression strength standard value of concrete. 
(2)calculation method of axial compression ration

$$
n=N / N_{0}
$$

In the formula, $N$-axial load; $N_{o}$ - axial compression capacity of steel tube steel reinforced concrete composite column.

(3) calculation method of shear span ratio $\lambda$

$$
\lambda=\frac{L}{D}
$$

In the formula, $L, D$ - the height and external diameter of steel tube steel reinforced concrete composite column.

Selection of Component. The selection of component parameter is the key step for calculation and analysis, and reasonable parameter selection will take to get twice the result with half the effort.

Tab. 1 shear component parameters of steel tube filled with steel-reinforced concrete composite column

\begin{tabular}{ccccccccc}
\hline $\begin{array}{c}\text { Serial } \\
\text { number }\end{array}$ & $\begin{array}{c}\text { Component } \\
\text { size } \\
(\mathrm{D} \times \mathrm{t} \times \mathrm{l}) /(\mathrm{mm})\end{array}$ & $\begin{array}{c}\text { Displacement } \\
\text { direction }\end{array}$ & $\begin{array}{c}f_{c k} / \\
(\mathrm{MPa})\end{array}$ & $\begin{array}{c}f_{s k} / \\
(\mathrm{MPa})\end{array}$ & $\begin{array}{c}f_{t k} / \\
(\mathrm{MPa})\end{array}$ & $\theta$ & $\lambda$ & $\mathrm{n}$ \\
\hline $\mathrm{A}-1$ & $160 \times 4 \times 500$ & Strong axis & $\mathrm{C} 70$ & 235 & 235 & 0.22 & 3.125 & 0 \\
A-2 & $160 \times 4 \times 500$ & Weak axis & $\mathrm{C} 70$ & 235 & 235 & 0.22 & 3.125 & 0 \\
B-1 & $160 \times 5 \times 500$ & Strong axis & $\mathrm{C} 70$ & 235 & 235 & 0.28 & 3.125 & 0 \\
B-2 & $160 \times 5 \times 500$ & Weak axis & $\mathrm{C} 70$ & 235 & 235 & 0.28 & 3.125 & 0 \\
C-1 & $160 \times 6 \times 500$ & Strong axis & $\mathrm{C} 70$ & 235 & 235 & 0.34 & 3.125 & 0 \\
C-2 & $160 \times 6 \times 500$ & Weak axis & C70 & 235 & 235 & 0.34 & 3.125 & 0 \\
G-1 & $160 \times 5 \times 300$ & Strong axis & C70 & 235 & 235 & 0.28 & 1.875 & 0 \\
G-2 & $160 \times 5 \times 700$ & Strong axis & C70 & 235 & 235 & 0.28 & 4.375 & 0 \\
H-1 & $160 \times 5 \times 500$ & Strong axis & C70 & 235 & 235 & 0.28 & 3.125 & 0.4 \\
H-2 & $160 \times 5 \times 500$ & Strong axis & C70 & 235 & 235 & 0.28 & 3.125 & 0.8
\end{tabular}

In the table, $\theta$ : effect of restraint coefficient $\lambda$ :shear span ratio $n$ :axial compression ratio

\section{Analysis of Parameter}

The Coefficient of Constraint Effect. In this paper, by changing the wall thickness of steel tube ,we change the coefficient of restraint effect of steel tube steel reinforced concrete column. In this article,we select the steel tubes the wall thickness of which are respectively $4 \mathrm{~mm}, 5 \mathrm{~mm}, 6$ $\mathrm{mm}$, taking component A - 1, B-1, C - 1 to calculation analysis, obtain the P - U curve as shown in figure 1. 


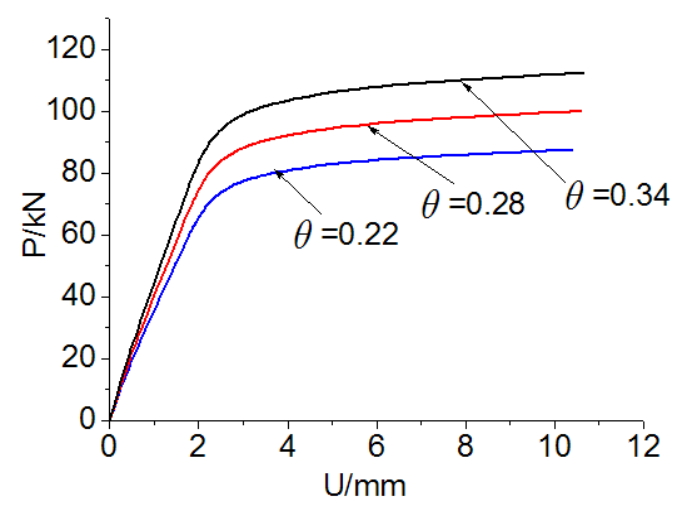

Fig. 1 P-U curve of different constraint effect coefficient

From the P - U curve we can analyze:

(1) with the increase of coefficient of restraint effect, the shear capacity of steel tube steel reinforced concrete column is stronger.

(2) The slope of the elastic stage increases gradually with the increase of coefficient of constraint effect.This is because that although with the increase of coefficient of restraint effect, elastic modulus of steel pipe has no change, the ratio taken up by steel tube of elastic modulus increases, resulting in the increase of elastic modulus of the whole component.

(3) On the whole, the shear bearing capacity of composite components of different coefficient of restraint effect doesn't immediately down after the yield point.

Shear Span Ratio. Short and thick component has high bearing capacity, good stability; Long and thin components easily exert under the action of eccentric load and horizontal load, the bending deformation and instability. So reasonable qualified shear span ratio of components is particularly important. This article analyzes three different shear span ratio artifacts, $\mathrm{B}-1, \mathrm{G}-1$ and $\mathrm{G}-2$, using simulation analysis, getting the $\mathrm{P}$ - U curve as shown in figure2.

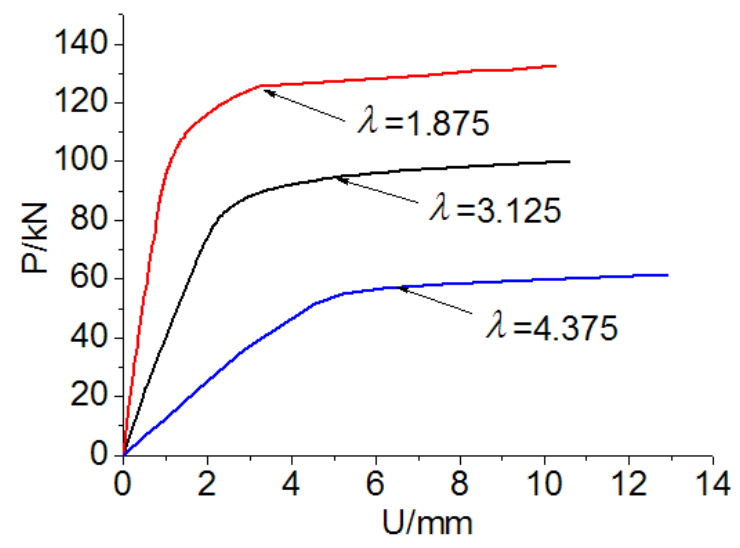

Fig. 2 the P-U curve of different shear span ratio

We can see from the diagram, the influence of shear span ratio on shear bearing capacity of components is very serious. It is embodied in:

(1)Elastic Phases: the elastic modulus gradually reduces with the increase of slenderness ratio.

(2) the yield stage: the smaller the shear span ratio is, the higher the yield strength is . The greater shear span ratio is, the lower the yield strength is. The limited bearing capacity of component 5-1 is lower half than that of component 5-2.

(3)Although the influence of shear span ratio is very serious, after the yield stage, the shear bearing capacity has no drop, suggesting that artifacts still keeps good ductility.

Axial Compression Ratio. Pillars in the actual application is generally loaded stress state, either the axial compression or the eccentric compression. This article selects the component 2-1, 8-1, and8-2 for calculation and analysis. Way of exerting load are shown in figure 3. 


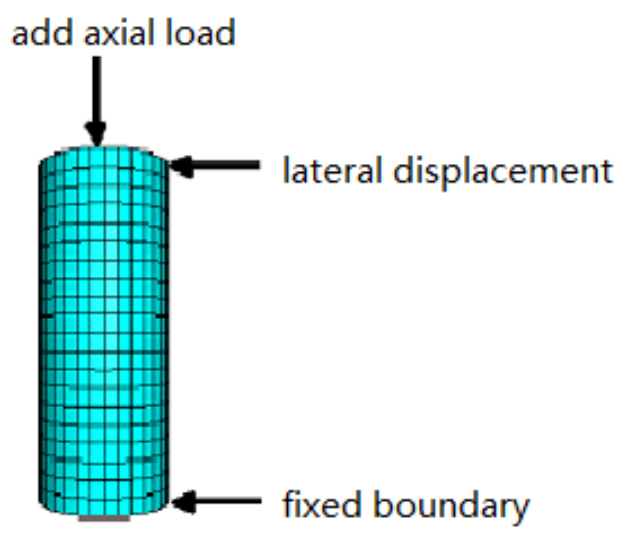

Fig. 3 jointly applied axial force and shear boundary conditions

Adopting two steps, the first step is to exert the axial pressure, the second step is to exert lateral shear. Through calculation and analysis, the P - U curve are shown in figure 4.

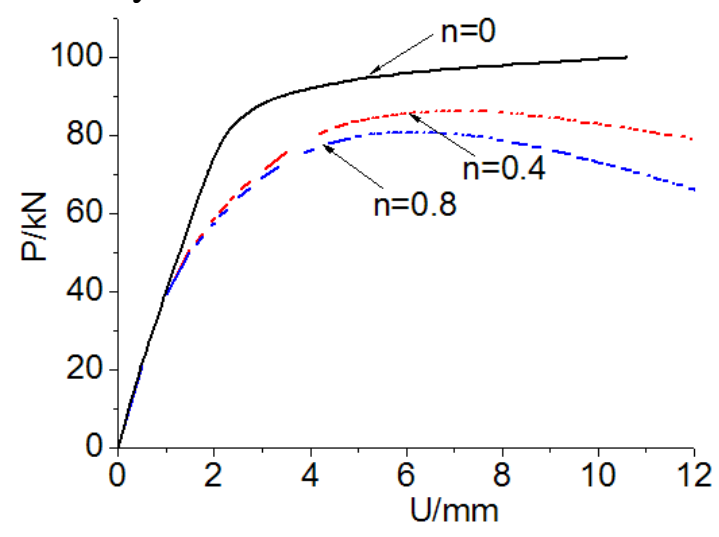

Fig. 4 the P-U curve of different axial compression ratio

From P - U curve of different axial compression ratio, it can be seen:

(1) the elastic stage: in the elastic stage, no matter what kind of components of axial compression ratio, the elastic modulus are consistent.

(2)the yield stage: due to the effect of pressure, the shear performance of steel pipe, steel framework and concrete reduces. what is more important is the decrease of the strength of the concrete.

(3) the ductility analysis: when the $\mathrm{n}$ equals to 0,the component has good ductility. In the late stages, the shear bearing capacity has slight increase. When the $\mathrm{n}$ equals to 0.4 under the action of axial pressure, in the late loading, the shear capacity has begun to decrease, so as the ductility.

\section{Conclusion}

In this paper, adopting the finite element model of ABAQUS established in chapter two, selecting the reasonable component parameters, we calculate and analyze the shear capacity of the steel tube steel reinforced concrete composite column under the effect of lateral horizontal displacement. Using P - U curve got by calculation and analysis, we analyze the three main parameters, including: coefficient of restraint effect, shear span ratio, axial compression ratio and their effect on the $\mathrm{P}-\mathrm{U}$ curve of steel pipe steel reinforced concrete composite column shear component.

\section{Acknowledgement}

It is a project supported by National Science Foundation (51308347) . 
It is a project supported by Shenyang Science Plan project (F13-171-9-00).

It is a project supported by Shenyang Science Plan project (F14-028-2-00).

It is a project supported by Shenyang Science Plan project (F14-210-6-00).

It is a project supported by Liaoning Science public research funds(2014004025).

\section{References}

[1] Lianguang Wang. The theory and calculation of steel and concrete composite structure[M]. Beijing: Science Press, 2005.

[2] Guoliang Bai, Fuhua Qin. The principle and design of steel reinforced concrete[M]. Shanghai: Shanghai Science Technology Press, 2000.

[3] Fam A, QieF S, Rizkalla S. Concrete-Filled Steel Tubes Subjected to Axial Compression and Lateral Cyclic Loads[J]. Journal of Structural Engineering, 2004, 130(4): 631-640.

[4] Linhai Han, Youfu Yang. Modern technology of steel tube concrete[M]. Beijing: China Architecture Industry Press, 2004.

[5] X L ZHAO, R GRZEBIETA, M ELCHALAKANI. Tests of Concrete-Filled Double Skin Circular Hollow Sections[C]. First Inter. Confer. on Steel \&Composite Structures. Pusan, Korea, June, 2001: 283-290.

[6] Han L H, Tao Z, Zhao X L, Concrete-Filled Double Skin (SHS Outer and CHS Inner) Steel Tubular Beam-Columns [ J]. Thin-Wall Structures, 2004, 42 (9): 1329-1355.

[7] Zhong Tao, Linhai Han, Hong Huang. The mechanical properties research on eccentric compression column of The hollow interlayer steel tube concrete [J]. Journal of civil engineering, 2003, 36(2):33-40. 